\title{
Future Scenarios for the European Higher Education Area: Exploring the Possibilities of "Experimentalist Governance"
}

\author{
Robert Harmsen
}

\section{Introduction}

Even as the European Higher Education Area (EHEA) formally came into being at the 2010 Budapest-Vienna ministerial conference, a growing sense appeared to be taking hold among participants that the Bologna Process (BP) had, to a significant extent, "exhausted" itself after a little more than a decade of existence. That sense of exhaustion was, in some respects, undoubtedly a positive development insofar as it could be likened to the exhaustion of a marathon runner who has completed the race. In less lyrical terms, the process appeared exhausted insofar as it had succeeded in achieving many of its initial goals, particularly at the level of the enunciation and acceptance of broad policy templates. As a commissioned independent assessment concluded at the time, "Most 'architectural' elements of the EHEA, i.e. those involving legislation and national regulation, have been implemented in most countries" (Westerheijden 2010, p. 5). At the same time, however, this underlying sense of exhaustion also had a more negative dimension. Here it appears rather more as an exhaustion born of frustration, of recognizing that perhaps a plateau had been reached from which further advances might not be possible, or would be possible only by overcoming inordinately difficult obstacles. Those frustrations, in large part, reflect the difficulties of on the ground implementation where, as the assessment report also highlighted, institutional and program level responses were "still wanting" (Ibid).

Given this situation, it would not be surprising if there were to be a (renewed) tendency toward questioning the "soft law" foundations of the EHEA as it has developed to date-i.e. the essentially non-binding character of the process, which seeks to foster policy learning through the establishment of shared understandings of best practice, processes of national reporting, and attendant peer review.

\footnotetext{
R. Harmsen ( $\square)$

Institute of Political Science, University of Luxembourg, Luxembourg City, Luxembourg e-mail: robert.harmsen@uni.lu
}

A. Curaj et al. (eds.), The European Higher Education Area,

DOI 10.1007/978-3-319-20877-0_48 
These soft law moorings have generated a degree of criticism in the scholarly literature. Most prominently, Garben $(2010,2011)$ has advanced a comparatively broad-based critique of the soft law character of the Bologna Process, making the case for the putative superiority of a regulation of the area by way of conventional, "hard" European Union (EU) law-at least as regards those EHEA participating states that are also EU member states. In so doing, she highlighted what she regarded to be fundamental procedural failings as regards the democracy and transparency of the process, as well as related substantive shortcomings concerned with its lack of effectiveness. In this, she joined a wider body of criticism of the so-called new modes of governance, principally concerned with what are taken to be its negative consequences for both parliamentary and legal accountability (cf. Idema and Keleman 2006).

Such criticisms undoubtedly have a degree of validity; issues of both accountability and effectiveness do arise in the context of the process, as indeed - it might be added - of governance processes more generally. The question that needs to be posed, however, is whether a hard law alternative is either a practical, or necessarily a superior, option.

The question of practicality is a straightforward one. Bologna has soft law in its DNA, and is - in the literal sense-practically inconceivable in another form. Following a now well-known sequence of events, it was through the development of loose forms of cooperation deliberately placed outside of the remit of the EU that a European higher education (HE) policy space was finally created (cf. Muller and Ravinet 2008), overcoming the longstanding and sometimes fierce national resistance which had long met European Commission initiatives to move in this direction within an EU framework (cf. Corbett 2005). It is fair to say that little has changed as regards this underlying dynamic in the intervening years. If states have become more comfortable in discussing higher education policy in European fora, they have shown no particular willingness to cede control over this chasse gardée of national policy. Moreover, it is evident that the development of formal regulation in the framework of a (currently) 47 member pan-European process, extending well beyond the EU 28, is a political non-starter. As a practical matter, the EHEA will "sink or swim" on the basis of its ability to make soft law structures work; there is no politically realistic "hardening" alternative.

The argument could, however, further be made that, even were such a hardening to be politically possible, it would not be substantively desirable. Insofar as the Bologna Process has been successful in creating a common European "language" of higher education policy (cf. Zgaga 2012), with widely shared points of comparison, it has done so through the fostering of consensual dialogue, where no threat of imposed solutions - of a "shadow of hierarchy" to use the jargon of the public policy literature-hangs in the balance. It is this absence of compulsion that has opened possibilities for policy learning, which have been significantly - if unevenly - seized. It is by no means certain that a hard law regime, even if it were it to be possible, would produce better results. Given the sensitivity of the area, the risk would rather be that any hypothetical moves toward a formal regulatory regime would produce substantial national disengagement and/or non-compliance, while 
undermining the strong potential learning dynamics engendered by the existing, looser forms of cooperation.

It is thus on this basis that the present paper proceeds to examine the future of the EHEA as a governance process, seeking to probe how soft law instruments may be better developed so as to introduce a renewed dynamism into an "exhausted" process. To that end, a model of "experimentalist governance", following Sabel and Zeitlin (Sabel and Zeitlin 2008, 2010), is first introduced below. Their four-stage model is then mapped on to an account of the governance of the Bologna Process. This mapping exercise particularly highlights the existence of systemic impediments preventing the development of strong dynamics of iterative policy learning connecting the national and the European levels. The final major section of the paper then seeks to draw lessons from this analysis, looking at the ways in which such impediments to policy learning might be removed or alleviated. Attention is focused successively on the relationship of expertise (and experts) to the wider policy process; the representativeness of European-level stakeholders; the higher education policy discourse of the European Commission; and the reframing of national higher education debates in terms which, over fifteen years after the Bologna Declaration, should now be seen as moving to a "post-reform" phase. Overall, a sketch is drawn of a series of plausible developmental paths, which may provide a means of both serving individual actor interests and the wider goal of further developing a robust pan-European higher education policy forum.

\section{Unpacking the New Modes of Governance}

The new modes of governance are most readily associated with the development of the so-called Open Method of Coordination (OMC) within the framework of the European Union. The OMC gained prominence as a generalized governance template in the context of the adoption of the Lisbon Agenda in the early 2000s, though the core idea of recourse to soft law instruments of governance may be traced a bit further back, at least to the 1997 European Employment Strategy and the so-called "Luxembourg Process". The BP/EHEA may be understood in relation to this, though with two caveats. The one, obviously, is the simple recognition that we are concerned with a pan-European process extending well beyond the EU. The other, perhaps somewhat less evidently, is that the BP/EHEA does not have a governance or process dimension as an objective-i.e. the OMC, at least in part, sought to foster more open or participatory forms of governance as something of a concomitant goal to the development of policy cooperation in given sectors. This is not true per se of the BP, whose launch dynamics appear rooted firmly and exclusively in reform agendas restricted to the higher education policy sector alone.

Nonetheless, though the BP/EHEA does not have these wider "democratizing" goals, we may nonetheless draw on these approaches as a means of understanding the functioning of the process itself, most particularly with a view to diagnosing its eventual shortcomings. To this end, I will take as my point of departure Sabel and 
Zeitlin's somewhat stylized or ideal-type model of "experimentalist governance" in the EU (Sabel and Zeitlin 2008, 2010). This model sets out a four-stage policy process, which may be presented as follows:

\section{Goal Setting}

The member states and EU institutions jointly establish framework goals and measures for their achievement.

2. Delegated Responsibility

Lower level authorities (regulators, ministries, etc.) are "given the free-dom to achieve these ends as they see fit" (Sabel and Zeitlin 2010, p. 2).

\section{Reporting and Peer Review}

As the counterpart to this autonomy, however, the lower level authorities must report regularly on their activities, and submit themselves to processes of peer review.

\section{Critical Re-evaluation and Policy Learning}

Framework goals, methods, etc. are themselves periodically reviewed, "augmented by such new participants whose views come to be seen as indispensable to full and fair deliberation" (Sabel and Zeitlin 2010, p. 3).

While the first three phases of the process as defined by Sabel and Zeitlin largely correspond to the "official" version of the OMC as advanced by the EU itself, ${ }^{1}$ the fourth and final phase points to a potentially more fundamental shift in the nature of the policy process, tied to what the authors term "democratizing destabilization". In effect, the intention is to effect a gradual opening out of the policy process - in the senses of both inclusivity and transparency - so as to allow for the expression of new ideas capable of shaking up_- "destabilizing" - the existing policy consensus. This destabilization is further situated relative to the underlying conception of experimentalist governance as fostering "directly deliberative polyarchy", i.e. comparatively decentralized policy spaces privileging collective, reasoned discussions.

One need not, however, necessarily go as far as the argument for a systemic or structural destabilization in order to tap into the underlying logic of experimentalist governance. In effect, that which is being pointed to is the necessity to conceive of a form of iterative policy learning as the key to the functioning of the model. If experimentalist governance is to have a dynamic or distinctive rationale as a mode of policymaking, it is through the fostering of such "learning" processes-i.e. allowing for forms of comparatively open-ended or expansive deliberation, conducive to innovation, such as are unlikely to be promoted by more conventional "hard" policy processes driven by more immediate interests and outcomes. At least, as Radaelli (2003, p. 8) underlined in an early study of the OMC, it is this core premise of "a governance architecture based on incentives for learning" that allows proponents of the OMC to make a plausible claim for this potentially being "better

\footnotetext{
${ }^{1}$ See http://europa.eu/legislation_summaries/glossary/open_method_coordination_en.htm. Website last accessed 2.01.2015.
} 
governance", rather than merely a "second-best option" when hard governance instruments are not reasonably available.

This slightly modified version of the Sabel and Zeitlin model now established, the following three sections of the paper will map the BP/EHEA relative to this ideal-type policy process. The relatively unproblematic stages of goal setting and delegation are first briefly discussed. Somewhat more attention is then paid to the rather more problematic area of reporting and peer review. Finally, systemic shortcomings are highlighted as regards the final, learning phase of the model. As already noted in the introduction, it is this absence of a strong capacity to generate iterative policy learning that is then principally addressed in the following part of the paper, setting out the terms for a possible reform of key aspects of the process so as to enhance its learning capacity.

\section{Mapping the Governance of the Bologna Process}

\subsection{Setting Goals and Delegating Responsibilities}

The BP/EHEA for the most part rather unproblematically conforms to the first two dimensions of the model, though somewhat distancing itself from the ideal-type over time. The Bologna Declaration set out a series of (six) clearly delineated objectives with relatively broad margins of interpretation, whose detailed translation was then left to the competent national or sub-national authorities - e.g. calling for the "adoption of easily readable and comparable degrees", based "on two main cycles", which sets a clear direction without, however, prescribing particular structures. The early development of Bologna, moreover, could be seen as focusing on an interconnected set of goals concerned with mobility, comparability and quality assurance.

This balance, relative to the ideal-type of experimentalist governance, was then somewhat blurred in the later development of the process. Latterly, the trend has been to add further topics or areas for discussion, while eschewing more specific goal setting. Thus, for example, wide-ranging topics such as the relationship of the EHEA to the European Research Area (ERA), "lifelong learning", and the "social dimension" have been added — but for the most part without clear objectives being agreed by the participating states comparable to those seen in the earlier stages of the process.

The absence of goal setting in this way does not, of course, preclude meaningful discussions in transnational fora or the opportunity to share "best practice". Comparative data may also, of course, be gathered under these rubrics, surveying national patterns and practices. The absence of specifically defined objectives does, nonetheless, have inescapable implications as regards the more direct use of benchmarking and peer review techniques. 


\subsection{Reporting and Peer Review}

Overall, this is a somewhat more problematic phase of the process. Some commentators have viewed this as a "success story". Ravinet (2008), for example, argues that it is essentially through the effective use of benchmarking and peer review that the Bologna Process may be seen to have gone from a system of "voluntary participation" to one of "monitored cooperation". Following her analysis, "countries feel increasingly bound by their commitments" because of: (1) The multiplication of information sources acting as a check on the accuracy of national reports and (2) The strength of socialization pressures ("naming and shaming") on poor performers by their peers to effect the necessary reforms.

This appears to be, however, a somewhat overly positive or optimistic account of the process, where at a minimum a marked unevenness of implementation has routinely been cited as a major problem (Amaral and Veiga 2012). These are also findings which stand squarely at odds with the findings of Dr. Gangolf Braband and myself in our 2010-2012 "Euro-Uni" research project. ${ }^{2}$ In our interview sample, all European-level participants highlighted the excessive presence of "green" in BP benchmarking exercises (indicating full achievement of the relevant objective in a "traffic light" system), noting inter alia the difficulty to "dissociate implementation from prestige" ${ }^{3}$ (particularly in the case of generally poorly performing states). National level participants, conversely (and predictably), defended the robustness of their reporting techniques and attendant data, but even here not in terms which would back the second - socialization - component of Ravinet's analysis. While stressing that they accurately reported outcomes, national officials nonetheless equally stressed that the use made of the results-i.e. whether it would be a spur to (further) reform - was essentially determined by national agendas. "European pressure", in other words, largely came into play only where this pressure corresponded to prior (often "uploaded") national commitments. In the words of one long-serving national official, "You put something on the European agenda because it suits your own domestic needs", as such "It creates a pressure to follow up a commitment you made in the first place. It is a bit of a chicken and egg question." ${ }^{4}$

The 2012 BP Implementation Report also appeared to acknowledge this more critical reading of the reporting and peer review process. The report, tellingly, noted that "the colour dark green is less prevalent in some action lines than before" (EACEA 2012, p. 7), reflecting "a more nuanced insight" as regards the yardsticks

\footnotetext{
${ }^{2}$ The project, funded as a competitively awarded internal research project by the University of Luxembourg, sought to examine the dialogical dynamics leading to the creation of a "higher education policy space" spanning the national and European levels. In the course of our research, we conducted semi-structured interviews with 15 senior national and European-level policymakers, focusing on the European institutions and selected West European states. See further Harmsen (2013).

${ }^{3}$ Interview with a senior European-level official, 22.07.2011.

${ }^{4}$ Interview with a senior national-level official, 06.06.2012.
} 
used for measurement or an extension in the scope of the indicator. The affirmation, obviously, is one of improvement - but in so doing also acknowledges the fairly widespread sense of some of the limitations of the (previous) reporting system.

An overall balance sheet of the (in-)effectiveness of the reporting process is beyond the scope of this short paper, but the broad tone of the 2012 report would seem to capture the underlying reality. Essentially, it is clear that the process of reporting and peer review has progressively improved over time. Primary information gathering has become more systematic, external checks have been multiplied, and the evaluation of data has become more consistent. This does not preclude the possibility of (egregious) national misreporting in individual casesactors who "manipulate the information they provide so as to show themselves, deceptively, to best advantage" (Sabel and Zeitlin 2010, p. 13). It equally must be qualified by an awareness of the possible limitations of the sources used for the triangulation of data, potentially subject to the same unevenness as the primary data which they are meant to check (cf. Geven 2012). It does, however, point to a situation in which it could reasonably be argued that the mechanisms of reporting and peer review have attained a minimum level of robustness such that this is not/no longer the weak link in the chain of a model of experimentalist governance. At the level of the overall process, the quality of the information available appears broadly such as to allow for meaningful, evidence-based deliberation. If this deliberation has not taken hold in the terms or to the extent that one might have expected, the key thus lies elsewhere - as discussed below.

\subsection{Critical Re-evaluation and Policy Learning}

Relative to the analysis above, the question then becomes one, beyond information gathering, of whether and how the BP feeds back into national policy processes. Does it promote critical engagement, and widening participation, in a manner which would allow for "democratizing destabilization" in the terms of Sabel and Zeitlin? Or perhaps, more modestly, as suggested above, does it facilitate forms of iterative policy learning?

Here the indications are quite strongly negative; there appear to be significant disconnects between the BP/EHEA policy arena and its national counterparts. On the one hand, at a relatively diffuse level, there appears to be comparatively little "Bologna awareness" on the ground. On the other hand, where comparatively strong traces of the BP may be found in national debates, it is often used by national governments as a means of restricting rather than fostering debates surrounding $\mathrm{HE}$ policy. A broadly constructed image of "Bologna" is, in such scenarios, used to legitimate wide-ranging HE reform programs by means of a strategy of "discursive closure". 


\subsection{1 "Bologna Awareness"}

Veiga's (2010) comparative study of the (non-)embedding of the BP at institutional level in seven comprehensive universities in seven different national contexts offers a strong indication of the relatively limited penetration of the process at grassroots level. Relative to the present context, Veiga (2010, p. 377) notes that "the perceptions of Bologna as a policy process remain relatively low". As she underlines, there was little effort by the "pays politique" to raise awareness within the "pays réel", resulting particularly in a very limited awareness of the underlying rationales for reform. At the political level, the BP came to be significantly translated as a "compliant action"- a sort of self-referential mimetism apparently unconnected to deeper policy concerns.

A somewhat different picture emerges when moving from policy process to policy implementation, as here aspects of the BP touch on the daily realities of academics, students, and administrators. Even here, however, significant aspects of the process, including legal framework, convergence of degree structures, and benchmarking activities, generated high proportions of "suspended opinions" among respondents. Moreover, insofar as the differing stakeholder groups might be differentiated, generally higher levels of awareness and engagement tended to be found amongst university administrators, reinforcing the managerial image of the process.

The overall portrait is thus one of generally low awareness of Bologna as a wider policy process, suggesting in itself little prospect for the type of expansive, participatory "destabilizing democratization" mooted in the original Sabel and Zeitlin model to take hold. This, in turn, points to the possibility of a more strategic manipulation of Bologna norms by centrally placed governmental actors, following a logic of what is presently termed "discursive closure".

\subsection{2 "Discursive Closure"}

Moving to strategies of "discursive closure", 5 it is no longer simply a matter of the "non-penetration" of Bologna norms, but rather of the strategic use of those norms by centrally placed actors so as to reframe-usually in a restrictive manner-higher education debates in other policy arenas. Broadly, where Bologna discourses have been strategically constructed in this manner, one might identify West European and EU accession state versions of the pattern. ${ }^{6}$

\footnotetext{
${ }^{5}$ The term is borrowed from Dostal's (2004) study of the Organization for Economic Cooperation and Development (OECD), though presently conceptualized in a somewhat different manner.

${ }^{6}$ It should be underlined that the present examples concern only selected instances of the political "use" (cf. Woll and Jacquot 2010) of Bologna norms, as distinct from the question of the wider patterns of differential implementation across the full range of participating states. These wider patterns are, for example, interestingly surveyed (and categorized) in Furlong (2010).
} 
In the West European version - seen in countries such as Austria, Germany, and Spain - the Bologna Process is used as an instrument of domestic leverage by governments seeking to legitimate much wider projects of structural reform in the higher education sector. The Bologna Process thus becomes "Bologna", often generating corresponding "anti-Bologna" oppositions.

In the German case, for example, Maesse (2010) has convincingly demonstrated how a technocratic "consensus discourse" was constructed around the Bologna Process, effectively seeking to restrict debates to questions over "how" reforms were to be realized, while correspondingly pushing questions concerned with the validity of the objectives themselves off the agenda. This, in turn, may be seen to have triggered what came to be styled as "anti-Bologna" protests, as reform opponents at least discursively took the governmental position at face value. These critics contested what they regarded to be the imposition of undesirable "European norms", associated with the "ravages of a neo-liberal modernization agenda" (see Charle and Soulié 2007; Schultheis et al. 2008). These contestations, moreover, extended over significant swathes of the sector-in the German case encompassing student groups, professors' associations, and prominent individual academics. As such, the "anti-Bologna" movement brought to the fore a broad range of concerns about curricular reform, accessibility, and professional status, as well as the more diffuse defence of a traditional, Humboldtian ideal of the university (cf. Thumfart and Braband, forthcoming). The strategic reconstruction of Bologna requirements, intended to restrict debate, could thus be seen to have reaped a predictable whirlwind, prompting a corresponding systemic opposition to the European process itself.

In contrast to the whirlwind seen in the West European pattern, the EU accession state pattern saw the Bologna Process substantially enter into the slipstream of the EU enlargement process. In the case of a number of CEE countries, Bologna came to be treated, or at least was effectively portrayed, as if it were a de facto part of EU conditionality - i.e. requirements which simply had to be met if one was to "join the club", and over which meaningful substantive debate was thus not possible. For example, Dakowska (forthcoming), in the case of Poland, highlights what she terms a "no alternative" narrative, used to push through a wide-ranging package of $\mathrm{HE}$ reforms. In similar terms, Deca (2015), analyzing the Romanian case, points to a "negative legitimation" strategy, whereby the emphasis was placed on the potentially isolating consequences of not embracing a broad series of putatively Bologna-inspired reforms.

Here too, therefore, Bologna may be associated with a "discursive closure" broadly used so as to close down rather than to open up wider higher education debates. Strikingly, however, corresponding "anti-Bologna" movements and discourses did not significantly take hold in the CEE countries, perhaps reflecting the wider asymmetric dynamics engendered by the temporally parallel process of EU enlargement (cf. Dakowska and Harmsen 2015). Indeed, in the Romanian case, Deca even notes the subsequent use by student groups of "Bologna norms" of stakeholder participation in their opposition to a later set of government $\mathrm{HE}$ reforms. 
This later Romanian example, however, appears to be very much the exception. Although this still requires more systematic research (focusing on the political uses rather more than the administrative implementation of Bologna), the general trend appears relatively clear. Far from fostering domestic higher education debates, Bologna appears rather more to have been used as an instrument to restrict them. This, to a significant extent, may be seen as a structural or systemic development. The main reason for governments to participate in an essentially normative policy arena such as Bologna, apart from the simple objective of recognition for more marginal members of the process, is to acquire discursive resources of a type that may be deployed in another policy arena with regulatory and/or redistributive consequences (cf. Harmsen 2013). That they should use the leverage which they have sought to give themselves is thus not surprising - but it does, effectively, choke off the possibility of iterative policy learning necessary for the process to sustain a dynamic development over time.

Can this be overcome? The failing presently identified is arguably a more generally symptomatic one for experimentalist or soft law modes of governance. It is not, however, irremediable - and the specific context of the EHEA offers perhaps a distinctively promising set of possibilities for re-engaging a more meaningful policy learning process by way of completing a feedback loop. To this end, four key lessons for the EHEA moving forward are drawn out below.

\section{Lessons for the EHEA}

Following from the analysis above, the four lessons below each concern possible developmental paths concerned with enhancing the capacity of the EHEA as a process to promote policy learning. Focused on removing impediments to learning at the system level, each lesson nonetheless also points to the manner in which the underlying interests of the actor(s) concerned could be strategically served by pursuing the suggested path.

\subsection{Resisting an "Epistemic Temptation"}

As the EHEA matures, there is a risk of the process turning in on itself-becoming, in the words of the 2010 assessment report (Westerheijden 2010, p. 9), "administration without much real impact on the reality of higher education." Following much the same logic, it is presently argued that the EHEA must not be allowed to go down a path where it is increasingly focused on comparatively narrow technical issues. Many in the process might feel themselves more comfortable with a narrowing agenda - an "epistemic temptation" - in which the EHEA comes to be seen as essentially concerned with issues of detailed implementation (if not simply 
mopping up), at the expense of its role as a wider policy forum. Such an isolated expertise is not, however, desirable, nor in the longer term sustainable.

It is clear that international organizations in general derive substantial authority through possessing or providing distinctive expertise; it is, simply put, an "authority" that derives from the ability to make "authoritative" pronouncements in a particular area, drawing on forms of specialized technical or professional knowledge (Barnett and Finnemore 2004, pp. 24-29). The ability of forms of international organization to assume such authority-irrespective of the (non-) existence of formal institutional arrangements - has perhaps been most influentially captured in Peter Haas' widely cited (and, in some respects, over extended) concept of "epistemic communities". Such communities, as Haas defines them, are "groups of professionals, often from a variety of different disciplines, which produce policy-relevant knowledge about complex technical issues" (Haas 1992, p. 16). The more that such groups are able to achieve a consensus in a given area, encompassing both substantive and causal beliefs as to the nature of good or effective policy, the more they may be able to set the agenda at the relative expense of more diffuse political concerns. The international organization of expertise may, in other words, displace the locus of decision-making from broad political to more technical fora, with the relative merits of policy solutions as viewed within the expert community correspondingly establishing the prevailing policy templates.

The BP clearly has elements of such an epistemic community. The process, in specific areas such as quality assurance or the development of qualifications frameworks, is invested with a specific technical competence. More widely, it can be seen to have created an expert community, possessed of its own thick "coordinative discourse" (cf. Schmidt 2006), allowing for the specialist discussion of policy issues.

The development of such areas of expertise and governance technologies is, moreover, a substantial strength of the process. It does, in the terms set out above, allow for the making of authoritative claims on the basis of specialist knowledge, which carry authority relative to political actors. This, in turn, serves to legitimate particular policy templates and to delegitimate others, substantially on the basis of the consensus that has emerged in the group.

The limits of such a "depoliticization" also, however, have to be recognized; an isolated expertise, turned in on itself and concerned only with relatively subsidiary questions of policy instrumentation, is likely simply to atrophy over time. On the one hand, if such a community is to exercise an influence, it must maintain clear channels of communication to the wider policy process and constellations of concerned actors (cf. Dunlop 2012). On the other hand, such a community must also itself remain open to wider influences, and in particular stay attuned to the evolving policy agenda.

In the present context, this focuses attention on two sets of crucial connections. At a macro-level, it is important that the work of the Bologna Follow-Up Group (BFUG) continue to be connected to a wider political process, as embodied in the (now) triennial ministerial conference, such that the linkages between detailed reforms and wider political agendas are not lost. At a micro-level, it is similarly 
necessary for national officials engaged with the BP to remain closely connected to national decision-making processes, capable of acting as influential mediators between the two (or multiple) policy arenas.

\subsection{Revisiting the Role of European-Level Stakeholders}

The (more) effective functioning of the EHEA in terms of an experimentalist model also requires that one revisit the role played by European-level stakeholders in the process. It should, in this respect, first be noted that sectoral stakeholders, in comparative terms, have enjoyed a strong and structured presence in the BP, and have in some instances clearly exercised an important influence (for example, on such issues as the development of the social dimension or student participation in governance structures). Relatively little attention has, however, been paid to their role as representative bodies - i.e. "Who" do they represent? and "How" do they represent (in the sense of the patterns of connections or disconnections between European peak-level bodies and national-level member organizations)?

Despite the substantial growth in the body of Bologna research, including a limited, but important component concerned with the policy process itself, we still know relatively little about the patterns of representation which have or have not developed. More specifically, the work of Manja Klemenčič (2011) has, to some extent, addressed these questions as regards student representation-noting, for example, the existence of something of a divide between a European Student Union (ESU) agenda “almost 'hijacked' by the issues related to the BP”' (Klemenčič 2011, pp. 1 and 18) and national agendas still more related to welfare and tuition issues (as well as national "misinterpretations" of the BP). We have, however, no comparable analysis on the institutional side as regards the European University Association (EUA) and/or the European Association of Institutions in Higher Education (EURASHE). Equally, we have little work that looks at the representativeness of the stakeholder community as a whole, including the relative absence of "line academics" from the process.

The intention in making this point, it should be underlined, is not one of making an a priori criticism. Rather, it is to call attention to the fact that these are major links in a representative process, which must be understood and critically scrutinized as such, if that process is to work in a reasonably inclusive and effective manner. This concern with the overall process, moreover, may also be seen to chime with the interests of the stakeholder groups themselves-whose longer term sustainability cannot be divorced from the quality of their connections with their grassroots membership and their effectiveness in representing the prevailing concerns of that membership.

In this regard, one must particularly bear in mind that the nature of European policy-making is often such that arenas create stakeholders, as much as stakeholders create arenas. European-level stakeholders, often supported by EU funding (Batory and Lindstrom 2011), have to some extent a vested interest in supporting the 
development of European-level policy solutions, which may or may not correspond to the priorities of their national constituent organizations. ${ }^{7}$ Whether or to what extent such a disconnect exists thus needs to be problematized, insofar as the (lack of) penetration or resonance of Bologna issues beyond the narrow EHEA arena itself may be substantially explicable with reference to the possible existence of such structurally induced shortcomings.

\subsection{Recasting the Higher Education Discourse of the European Commission}

In contrast to the discussion of the wider stakeholder community above, a critical look at the role of the European Commission rapidly turns to substantive criticism, given the development of an exceptionally narrow view of policy in the area, which singularly fails to exploit the considerable possibilities open to the institution. The Commission, through the propagation of its increasingly constrained "modernization" agenda, has become a significant deadweight as regards the potential development of a more dynamic European-level higher education forum. The modernization agenda in its current form (European Commission 2011), with its one-dimensional focus on the economic dimension of higher education alone, is both narrow and narrowing - i.e. the discourse in itself represents an impoverished view of higher education, and perhaps even more has the effect, given the pivotal role of the actor concerned (cf. Keeling 2006), of choking off potentially much richer dialogues.

The specific terms of the critique need perhaps be spelled out, as much of the problem, from the point of view of fostering wider dialogues facilitative of policy learning, stems from what appears to be a sort of reification of the Commission position around a narrowly defined orthodoxy over time. This, moreover, concerns not so much directly its position within the BP/EHEA per se, but rather its moves toward the development of a distinctive EU higher education policy arena, which strategically exploits the space opened up by the BP for other European-level initiatives.

The early phase of post-1999 positioning by the Commission appears readily comprehensible. Notably, its 2003 communication, on "The Role of Universities in the Europe of Knowledge", sketches out a broad and plausible survey of the sector at the time - not unfairly highlighting the "comparatively isolated universe" inhabited by (many) European universities "for a very long period of time" in relation to both their immediate social environment and the wider world (European Commission 2003, p. 22). Relative to this diagnosis, central questions for the sector

\footnotetext{
${ }^{7}$ See Cram (1993) on the European Commission as a "purposeful opportunist", strategically creating a demand for European-level action.
} 
are posed in relation to its growing economic relevance, in terms consonant with the EU's wider Lisbon Agenda.

By way of contrast, even a cursory glance at the Commission's 2011 communication points to this wider agenda having been lost. The title, indeed, rather gives the game away from the first page - "Supporting Jobs and Growth-An Agenda for the Modernisation of Europe's Higher Education Institutions". Higher education is simply subsumed under wider economic goals, with the structure of the paper itself further cashing out this logic. In contrast to the 2003 document, which starts with a vision of the sector and works out to seek interconnections, the 2011 document is structured almost entirely around the enunciation of policy priorities exogenous to the sector itself. Higher education as a distinct entity, with its own logics and purposes, seems to disappear from the screen.

This clearly poses serious problems for the wider development of meaningful European-level dialogues. In effect, it is this positioning by the Commission which substantially, if by no means exclusively, accounts for the often mooted characterization of "Bologna" as "neo-liberal", insofar as "European" policy in the higher education sector is identified with a narrowly defined "modernization". As a result, "Europe", in relation to higher education, is often identified with a narrow set of policy options, rather than a wider space of exchange-and rejected as such.

Relative to this, one might respectfully suggest that the Commission could and should play a rather different role in relation to the sector-shifting away from the role of advocate to that of honest broker. The sector would clearly be better served by a Commission more concerned with facilitating broad dialogues about higher education at the European level, within which its economic dimension would equally clearly continue to occupy a central (but no longer exclusive) role. At the same time, this would also appear to be in the strategic interest of the Commission itself, insofar as it is concerned to develop a more robust European-level policy arena in the sector. It would seem self-evident that such an arena, in an area of considerable national political sensitivity, will not be developed through an insistence on the predetermined acceptance of a narrowly defined agenda to the exclusion of a broader spectrum of alternatives. This failing, if left unaddressed, will continue to be a major brake on any serious development of the area, including that of a putative "modernization" itself.

\subsection{Reframing National Higher Education Policy Debates}

The final lesson returns us to national higher education debates, and the relative lack of penetration by or engagement with Bologna/the EHEA at the national level. As discussed in the previous section, part of the explanation for this shortcomingsuch that the feedback loop is not closed up so as to facilitate policy learning-lies in the pursuit by national governments of strategies of "discursive closure". Governments selectively use broadly defined "Bologna norms" to legitimate particular policy choices, correspondingly restricting wider policy debates. The 
government, in effect, sets itself up as the authoritative mediator between the national and the European arenas, and thus, at least from a purely strategic point of view, would have no interest in facilitating the opening of further channels of communication between those arenas. Insofar as this is true, why would governmental actors cede this strategic advantage?

Occasionally, perhaps, individual actors may listen to the "better angels of their nature" and, by acts of grace or charity, unilaterally withdraw from an advantageous position. A generalized outbreak of such altruism nonetheless appears no more likely here than in other walks of life. At a systemic level, the question to be posed is thus rather one of whether the strategic advantage remains a strategic advantage - and here it might reasonably be suggested that the leitmotif of the BP/EHEA has changed, and changed in such a way as to make it more amenable to dialogue.

The first phase of Bologna was undoubtedly marked by an ethos of "reform". Already the 1998 Sorbonne meeting set the tone for a process whereby the creation of a European framework was primarily conceived in terms intended to leverage difficult domestic reforms (see, for example, Haskel 2009). In the more than fifteen years since the launch of the process, however, major changes have occurred, fundamentally reshaping the context for at least a lead group of countries. Significant reforms have been realized, both in connection with the BP and more widely. This has, moreover, correspondingly reshaped the landscape of national higher education systems and the attendant demands of policy. There are, evidently, a great variety of national situations, having undergone very uneven degrees of change relative to highly diverse starting points. Nevertheless, at the level of the process as a whole, it no longer makes sense to speak of an agenda dominated by "reform" in the same terms as at the outset. Different problems and dynamics must inevitably come to the fore as the EHEA enters a "post-reform" phase.

Most evidently, at least for those countries having undergone major reforms, the focus has broadly shifted to questions of system steering. Again with due recognition of the diversity of national systems concerned, the broad thrust of reforms may nonetheless be described in terms of having moved from what were often comparatively hierarchical "command and control" models, with a strongly interventionist governmental presence, to systems which grant higher education institutions considerably more formal autonomy with, as a counterpart, new or extended mechanisms of external accountability (cf. Harmsen 2014). Correspondingly, that which policymakers now require is rather less the leverage of external legitimation, and rather more new understandings of how to operate the levers of a complex system, so as to allow for a necessary and desirable institutional-level autonomy, while also permitting the degree of steering required to secure overall system-level policy goals. Operating in such an environment thus requires new governance technologies, laying a particular emphasis on dialogue or communication-i.e. "steering", by definition, requires a connectedness and responsiveness which militates against the type of unilateral "discursive closure" identified earlier.

The questions posed for the EHEA are those of how it might engage this changed reality, and this on two levels: 
- How, within its remit, may the EHEA contribute to dialogues about "best practice" in terms of developing policy instruments related to the steering of complex higher education systems (and this in a context where it is unlikely that the process will move significantly toward encompassing governance or management issues per se)?

- How, in developing these substantive dialogues, might the process itself be further opened out - drawing in and engaging a broader range of actors, particularly national-level stakeholders, than is presently the case?

If there are no easy answers to these questions, the broad direction of development nevertheless appears rather clear and rather clearly promising. A "post-reform" EHEA should, by the nature of the issues under discussion, be more amenable to the development of wider, more inclusive dialogues, having the potential to foster dynamic processes of policy learning.

\section{Conclusion}

The present analysis of potential future scenarios for the development of the EHEA, as outlined in the introduction, has been developed by a series of interlinked moves. The case for the inescapably soft law future of the process (if it is to have a sustained future) was first made, as a matter of both political realism and desirable policy development. This gave way, in turn, to an analysis of the governance of the $\mathrm{BP} / \mathrm{EHEA}$ to date, in relation to a prominent ideal-type model of experimentalist governance as developed by Sabel and Zeitlin. This mapping of the process in relation to the model identified the absence of a strong logic of iterative policy learning as its principal shortcoming. On this basis, four lessons were then drawn, pointing to potential developmental scenarios whereby significant impediments to policy learning might be removed-re-energizing the process as a whole in ways which further could reasonably be seen as serving the underlying interests of the actors concerned.

The identification of such possibilities does not, of course, equate with their realization. Here as elsewhere, in-built inertias will be strong. On the negative side of the ledger, it might also be noted that many of the difficulties noted above in the specific context of the BP/EHEA reflect more general problems that have also afflicted the operation of the EU's OMC (see, for example, de la Porte and Nanz 2004; Smismans 2008). The core issues of both accountability and effectiveness highlighted in the present case have similarly dogged other attempts at developing soft law modes of governance.

Relative to this more general pattern, however, the distinctiveness of the BP/EHEA should finally be underlined. Undoubtedly, as a pan-European body, the $\mathrm{BP} / \mathrm{EHEA}$ is faced with a diversity of situations extending well beyond that seen in the narrower EU context-raising, in some instances, questions of a basic governability that cannot be ignored. Yet, this very diversity - and even, paradoxically, 
the potential "ungovernability" of the process beyond a certain point - is also an asset. The EHEA, unlike the EU, casts no "shadow of hierarchy". The process may be opened out - in terms of both substantive issues and scope of participationwith no fear that it conceals an underlying threat of formal regulation by stealth within its structures. It is this very openness which needs to be seized and developed so as to facilitate the wider channels of policy learning discussed above.

For wider policy learning of this sort to take place, strategically placed actorsmost prominently, national governments and the European Commission-would themselves, of course, have to "learn" that their own wider interests may be better served by the fostering of more inclusive, structured dialogues. This is clearly neither automatic nor unproblematic. Returning to the introductory discussion of the possible exhaustion of the process, it is this step that may indeed finally prove to be a step too far. Yet, for the EHEA ultimately to succeed or fail as a learning process would, if nothing else, appear a fitting challenge.

Open Access This chapter is distributed under the terms of the Creative Commons Attribution Noncommercial License, which permits any noncommercial use, distribution, and reproduction in any medium, provided the original author(s) and source are credited.

\section{References}

Amaral, A., \& Veiga, A. (2012). Soft law and the implementation problems of the Bologna process. Educação, Sociedade \& Culturas, 32, 121-140.

Barnett, M., \& Finnemore, M. (2004). Rules for the world: International organizations in world politics. Ithaca, NY: Cornell University Press.

Batory, A., \& Lindstrom, N. (2011). The power of the purse: Supranational entrepreneurship, financial incentive, and european higher education policy. Governance: An International Journal of Policy, Administration, and Institutions, 24(2), 311-329.

Charle, C., \& Soulié, C. (Eds.). (2007). Les ravages de la «modernisation» universitaire en Europe. Paris: Editions Syllepse.

Corbett, A. (2005). Universities and the Europe of knowledge: Ideas, institutions and policy entrepreneurship in European Union higher education policy, 1955-2005. Basingstoke: Palgrave MacMillan.

Cram, L. (1993). Calling the tune without paying the piper? Social Policy Regulation: The Role of the Commission in European Community Social Policy. Policy and Politics, 21(2), 135-146.

Dakowska, D. (forthcoming). Bologna and higher education reform in post-communist transition: The case of Poland. In R. Harmsen \& N. Kauppi (Eds.), The Europeanisation of higher education and research policy: The Bologna process, the European Union and the International marketplace. Amsterdam/Leiden: Brill/Rodopi (European Studies series).

Dakowska, D., \& Harmsen, R. (2015). Laboratories of reform? The Europeanisation of higher education in Central and Eastern Europe, introduction to the special issue 'Europeanisation, internationalisation and higher education reforms in Central and Eastern Europe'. European Journal of Higher Education, 5(1), 4-17.

de la Porte, C., \& Nanz, P. (2004). The OMC-a deliberative-democratic mode of governance? The case of employment and pensions. Journal of European Public Policy, 11(2), 267-288.

Deca, L. (2015). International norms in the reform of romanian higher education: A discursive analysis. European Journal of Higher Education, 5(1), 34-48. 
Dostal, J. M. (2004). Campaigning on expertise: How the OECD framed EU welfare and labour market policies - and why success could trigger failure. Journal of European Public Policy, 11 (3), 440-460.

Dunlop, C. (2012). Epistemic communities. In M. Howlett, et al. (Eds.), Routledge handbook of public policy (pp. 229-243). London: Routledge.

EACEA, Education, Audiovisual and Culture Executive Agency. (2012). The European higher education area in 2012: Bologna process implementation report. Brussels.

European Commission. (2003). The role of the universities in the Europe of knowledge. COM (2003) 58 final.

European Commission. (2011). Supporting jobs and growth: An agenda for the modernisation of Europe's higher education system. COM(2011) 567 final.

Furlong, P. (2010). Bologna's deepening empire: Higher education policy in Europe. In K. Dyson \& A. Sepsos (Eds.), Which Europe? The politics of differentiated integration (pp. 293-307). Palgrave: Basingstoke.

Garben, S. (2010). The Bologna process: From a european law perspective. European Law Journal, 16(2), 186-210.

Garben, S. (2011). EU higher education law: The bologna process and harmonization by Stealth. Dordrecht: Wolters Kluwer.

Geven, K. (2012). Bologna through whose eyes? A meta-analysis of six generations of Bologna with students' eyes. Journal of the European Higher Education Area (4), 1-20.

Haas, P. (1992). Introduction: Epistemic communities and international policy coordination. International Organization, 46(1), 1-35.

Harmsen, R. (2013). The Bologna process and new modes of governance: Logics and limits of arena-shaping. Paper presented at the Thirteenth biennial conference of the European Union Studies Association, Baltimore, USA.

Harmsen, R. (2014). The governance of the global university: leadership and policy challenges. Raabe Handbook of Leadership and Governance in Higher Education, 2014(3), 36-52.

Haskel, B. (2009). Weak process, strong results: Cooperation in European higher education. In I. Tömmel \& A. Verdun (Eds.), Innovative governance in the European Union: The politics of multilevel policymaking (pp. 273-288). Boulder, CO: Lynne Rienner.

Idema, T., \& Keleman, D. R. (2006). New modes of governance, the open method of coordination and other fashionable red herring. Perspectives on European Politics and Society, 7(1), $108-123$.

Keeling, R. (2006). The Bologna process and the Lisbon research agenda: The European Commission's expanding role in higher education discourse. European Journal of Education, 4 (2), 203-223.

Klemenčič, M. (2011). Europeanisation of the 'European student movement'. Paper presented at the Twelfth biennial conference of the European Union Studies Association, Boston, USA.

Maesse, J. (2010). Die vielen stimmen des Bologna-Prozessess: Zur diskursiven Logik eines bildungspolitischen Programms. Bielefeld: Transcript.

Muller, P., \& Ravinet, P. (2008). Construire l'Europe en résistant à l'UE: Le cas du processus de Bologne. Revue internationale de politique comparée, 15(4), 653-665.

Radaelli, C. (2003). The open method of coordination: A new governance architecture for the European Union? Swedish Institute for European Policy Studies paper series.

Ravinet, P. (2008). From voluntary participation to monitored coordination: Why European Countries feel increasingly bound by their Commitment to the Bologna process. European Journal of Education, 43(3), 353-367.

Sabel, C. F., \& Zeitlin, J. (2008). Learning from difference: The new architecture of experimentalist governance in the EU. European Law Journal, 14(3), 271-327.

Sabel, C. F., \& Zeitlin, J. (Eds.). (2010). Experimentalist governance in the European Union: Towards a new architecture. Oxford: Oxford University Press.

Schmidt, V. (2006). Democracy in Europe: The EU and national polities. Oxford: Oxford University Press. 
Schultheis, F., et al. (Eds.). (2008). Le cauchemar de Humboldt: Les réformes de l'enseignement supérieur européen. Paris: Raisons d'Agir.

Smismans, S. (2008). New modes of governance and the participatory myth. West European Politics, 31(5), 874-895.

Thumfart, A., \& Braband, G. (forthcoming). Implementing the goals of the Bologna process in Germany: From indifference to protest. In R. Harmsen \& N. Kauppi (Eds.), The Europeanisation of higher education and research policy: The Bologna process, the European Union and the international marketplace. Amsterdam/Leiden: Brill/Rodop (European Studies series).

Veiga, A. (2010). Bologna and the institutionalisation of the European higher education area (doctoral thesis). University of Porto, Porto.

Westerheijden, D. F., et al. (2010). The first decade of working on the European higher education area: The Bologna process independent assessment. Retrieved from http://www.ond. vlaanderen.be/hogeronderwijs/bologna/2010_conference/documents/IndependentAssessment_ 1_DetailedRept.pdf

Woll, C., \& Jacquot, S. (2010). Using Europe: strategic action in multi-level politics. Comparative European Politics, 8(1), 110-126.

Zgaga, P. (2012). Reconsidering the EHEA principles: Is there a "Bologna philosophy". In A. Curaj, et al. (Eds.), European higher education at the crossroads: Between the Bologna process and national reforms (Part 1) (pp. 17-38). Dordrecht: Springer. 